oesophageal sphincter pressure in patients during general anaesthesia. Br J Anaesth1992; 69: 346-8.

3 Ansermino JM, Blogg CE. Cricoid pressure may prevent insertion of the laryngeal mask airway. Br J Anaesth 1992; 69: 465-7.

4 Tunstall ME. Failed intubation in the parturient (Editorial). Can J Anaesth 1989; 36: 611-3.

5 Tunstall $M E$, Sheikh $A$. Failed intubation protocol: oxygenation without aspiration. Clin Anaesth 1986; 4: 171-87.

\section{LMA for failed intubation (2)}

To the Editor:

Priscu et al. ' suggested that the priorities of the various failed intubation drills in obstetric patients should be changed and the LMA used at an early stage. However, it is our view that their use of the LMA in the patient reported was inappropriate and their suggestion is unjustified.

When the patient's lungs can be ventilated adequately with a face mask, the LMA confers no advantage except that jaw support is unnecessary. We agree with the view of King and Adams ${ }^{2}$ that "should ventilation be easy after failed intubation in an obstetric patient, insertion of the LMA would at the very least be meddlesome." In addition, lower oesophageal sphincter pressure has been shown to be significantly lowered with the use of the LMA when compared with the use of the face mask and Guedel airway, ${ }^{3}$ thus increasing the risk of regurgitation. The studies to date on the effect of the LMA on the incidence of the regurgitation show conflicting results. ${ }^{3-5}$ In this context, given our present state of knowledge, we would be cautious in recommending the use of the LMA in view of the potential for regurgitation. Furthermore, since the tip of the LMA lies below the level of the cricoid cartilage when the LMA is properly positioned, application of cricoid pressure hampers correct positioning of the LMA.

When ventilation cannot be maintained after efforts at tracheal intubation have failed, the LMA could be tried. This decision should be made at an early stage, as the LMA may not always provide adequate ventilation. Whether or not cricoid pressure should be released temporarily during insertion of the LMA is controversial. ${ }^{6,7}$ Once the LMA is inserted, cricoid pressure must be applied continuously until airway reflexes return; recovery of spontaneous respiration does not guarantee return of airway reflexes.

Therefore, we believe that in patients at high risk of pulmonary aspiration, the LMA should not be used when adequate ventilation can be achieved with a face mask with effective application of cricoid pressure.

\author{
Takashi Asai MD \\ Ian Appadurai FRCA \\ Department of Anaesthetics \\ University of Wales College of Medicine \\ Heath Park, Cardiff CF4 4XN \\ United Kingdom
}

\section{REFERENCES}

1 Priscu V, Priscu L, Soroker D. Laryngeal mask for failed intubation in emergency Caesarean section. Can J Anaesth 1992; 39: 893.

2 King TA, Adams AP. Failed tracheal intubation. $\mathrm{Br} \mathrm{J}$ Anaesth 1991; 65: 400-14.

3 Rabey PG, Murphy PJ, Langton JA, Barker P, Rowbotham $D J$. Effect of the laryngeal mask airway on the lower oesophageal sphincter during anaesthesia. $\mathrm{Br} \mathrm{J}$ Anaesth 1992; 69: 346-8.

4 Barker P, Murphy P, Langton JA, Rowbotham DJ. Regurgitation of gastric contents during general anaesthesia using the laryngeal mask airway. Br J Anaesth 1991; 67: $600 \mathrm{P}$.

5 El Mikatii N, Luthra AD, Healy TEJ, Mortimer AJ. Gastric regurgitation during general anaesthesia in the supine position with the laryngeal and face mask airways. $\mathrm{Br}$ J Anaesth 1992; 69: 529-30P.

6 Ansermino JM, Blogg CE. Cricoid pressure may prevent insertion of the laryngeal mask airway. $\mathrm{Br} \mathrm{J}$ Anaesth 1992; 69: 465-7.

7 Brimacombe J. Cricoid pressure and the laryngeal mask airway. (Letter). Anaesthesia 1991; 46: 986-7.

\section{LMA for failed intubation (3)}

To the Editor:

The most interesting feature of this case was the decision to convert to the LMA after adequate ventilation had been achieved with a face mask (FM). We would like to question whether this manoeuvre is appropriate in the non-fasted patient. To change from one form of airway management which has been found to be adequate with cricoid pressure (CP) applied, to an alternative where adequate oxygenation is not guaranteed is potentially hazardous. We feel this could only be advised if continued airway patency was in doubt or the risks of aspiration was considered substantially less with the alternative technique.

The concerns regarding the use of the LMA in the non-fasted patient include the interaction between CP and 
the LMA. A study on cadavers suggested that the LMA did not interfere with CP once in situ. ${ }^{\prime}$ There has been some uncertainty about the effect of CP on LMA insertion, ${ }^{2,3}$ but early results from a randomised, blinded study during conditions mimicking failed intubation indicate that insertion is successful in $90 \%$ of patients with CP applied.

Defining the position of the LMA in a failed intubation drill (FID) still requires discussion and we would like to suggest the following guidelines: the use of the LMA in failed intubation will usually follow unsuccessful use of the FM with CP applied. We would suggest that LMA insertion should be attempted initially with maintained $\mathrm{CP}$ and, if this fails, then a second attempt should be made with transient release of CP. If an adequate airway is still not achieved, then the FM should be reapplied without $\mathrm{CP}$ before resorting to a cricothyrotomy.

We feel that there may be a situation where the LMA could be a first-line alternative in a FID. If difficulty with the FM was anticipated, and considering that the optimal time for LMA insertion is before the patient's reflexes return, then it may be safer to opt for the LMA before the FM. However, the anaesthetist would need to be skilled at using the LMA and conditions must be suitable for LMA insertion. Finally, we would suggest that it would be safer to continue with the LMA or wake the patient rather than attempting blind intubation via the LMA since successful placement is uncertain.

\section{J. Brimacombe MB ChB FRCAnaes}

A. Berry MB ChB FRCAnaes

Department of Anaesthesia

Royal Perth Hospital

Wellington St, Perth 6001

Australia

\section{REFERENCES}

1 Strang $T I$. Does the laryngeal mask airway compromise cricoid pressure? Anaesthesia 1992; 47: 829-31.

2 Brimacombe J. Cricoid pressure and the laryngeal mask airway. Anaesthesia 1991; 46: 986-7.

3 Ansermino JM, Blogg CE. Failed trachea intubation at caesarean section and the laryngeal mask. B J Anaesth 1992; 69: 465-7.

\section{$R E P L Y$}

Thank you for the opportunity to answer to the letters of Drs. Levy, Asai and Appadurai, and Brimacombe and Berry. It is known that by the 34th week of pregnancy gastric emptying time can be prolonged by up to $60 \%$. In the case we presented ${ }^{2}$ the patient was fasting for more than 12 hours, and received a non-particulate antacid as part of the preoperative routine. The risk of gastric content aspiration was considered minor in our case. The findings of Rabey et al. ${ }^{3}$ are extremely interesting. Unfortunately, at the time we submitted our paper they were not yet printed. As Drs. Asai and Appadurai pointed out the studies to date on the effect of the laryngeal mask airway (LMA) on the incidence of the regurgitation show conflicting results and are very few. In our opinion this issue awaits further investigation. We agree that in the patient at high risk of gastric aspiration the decision to use the LMA must be carefully assessed against the risks involved, but nevertheless is an option that must be considered.

Virgil Priscu MD

Lilia Priscu MD

David Soroker MD

Department of Anesthesia

Kaplan Hospital, Rehovot

Affiliated to the Hebrew University

and Hadasah-Jerusalem, Israel

REFERENCES

1 Davison JS, Davison MC, Hay DM. Gastric emptying time in late pregnancy and labour. J Obst Gyn $\mathrm{Br}$ Commonw 1970; 77: 37-41.

2 Priscu V, Priscu L, Soroker D. Laryngeal Mask for failed intubation in emergency Caesarean section. Can J Anaesth 1992; 39: 693.

3 Rabey PG, Murphy PJ, Langton JA, Barker B, Rowbotham $D J$. Effect of the laryngeal mask airway on lower oesophageal sphincter pressure in patients during general anaesthesia. Br J Anaesth 1992; 69: 346-8.

\section{Addendum}

(re: Dr. Jan Davies' review of Aftermath of Death in the Book Review section of the May 1993 issue, page 475).

The sole North American publisher of Afiermath of Death (Hugh Selby, Editor) is Wm. W. Grant \& Sons, Inc. of Holmes Beach, Florida. The price is $\$ 53.00$ (U.S.).

\section{Erratum}

Tetzlaff JE, O'Hara JF Jr, Walsh MT. Potassium and anaesthesia. Can J Anaesth 1993; 40: 227-46.

Please note that the formula on page 228 should read:

$$
\mathrm{E}_{\mathrm{k}}=-61.5 \log \mathrm{K}_{\mathrm{i}} / \mathrm{K}_{\mathrm{e}}
$$

